\title{
Prognostic nomogram for overall survival in upper aerodigestive tract extranodal natural killer/T-cell lymphoma, nasal type, stages IE and IIE: A SEER-based study
}

\author{
GANGJIAN WANG, YU CHANG, XIAOLONG WU, XIN LI, LING LI and MINGZHI ZHANG
}

Department of Oncology, The First Affiliated Hospital of Zhengzhou University, Zhengzhou, Henan 450052, P.R. China

Received January 30, 2019; Accepted June 13, 2019

DOI: $10.3892 / 01.2019 .10719$

\begin{abstract}
The present study aimed to develop a widely accepted prognostic nomogram for stage IE and IIE extranodal natural killer/T-cell lymphoma (ENKTCL) of the upper aerodigestive tract by using the Surveillance, Epidemiology, and End Results program database. A total of 396 patients with ENKTCL were included in the present study and were divided into training $(n=280)$ and validation $(n=116)$ cohorts. The Kaplan-Meier method and Cox regression model were used to evaluate the prognostic value of multiple clinical parameters on overall survival. The $\mathrm{C}$-index and calibration curves were both used to determine the predictive and discriminatory capacities of the nomogram. In the training cohort, multivariate analysis demonstrated that age, primary site, radiation therapy and stage were independent prognostic factors. Nomograms with a $\mathrm{C}$-index of 0.717 in the training cohort and a C-index of 0.737 in the validation cohort were developed. The calibration curves reported excellent consistency between predicted and real survival in patients with ENKTCL. In addition, a subgroup analysis of 264 patients who were receiving chemotherapy revealed that based on chemotherapy, supplementation with radiation therapy was significantly beneficial to patients survival. In conclusion, the present study demonstrated that this prognostic model may serve as a novel tool for improving prediction of survival outcomes and may therefore be used in clinical applications.
\end{abstract}

\section{Introduction}

Extranodal natural killer/T-cell lymphoma (ENKTCL) is a highly aggressive type of lymphoma strongly associated with Epstein-Barr virus infection that has a poor clinical outcome, and the incidence of ENKTCL is higher in Asian and Latin American countries compared with Western countries $(1,2)$.

Correspondence to: Professor Mingzhi Zhang, Department of Oncology, The First Affiliated Hospital of Zhengzhou University, 1 Jianshe East Road, Zhengzhou, Henan 450052, P.R. China E-mail: mingzhi_zhang1@163.com

Key words: extranodal natural killer/T-cell lymphoma, prognostic nomogram, upper aerodigestive tract lymphoma, early-stage lymphoma
Most studies on ENKTCL are therefore based on the populations of eastern Asia, and Central and South America countries, and relatively little information about this disease in people from Western countries is available. Neoplastic cells express cytoplasmic-CD3e, CD56 and cytotoxic molecules. Most studies have reported a 5-year survival rate of $<50 \%$ (3-7). The Ann Arbor staging system, which was originally used in Hodgkin lymphoma, is useful to assess prognosis (8). Most ENKTCL cases comprise local lesions and $\sim 80 \%$ cases involve stage IE and IIE $(7,9,10)$. The treatment options and clinical characteristics of this disease have always been an important issue (11-13). Previously, anthracycline-containing chemotherapy regimens, including the cyclophosphamide, doxorubicin, vincristine and prednisolone regimen, were commonly used in advanced ENKTL treatment; however, they did not achieve satisfactory results (9). Currently, L-asparaginase-based regimens are the main treatment option (1). ENKTCL mainly originates from the upper aerodigestive tract (UADT), which usually involves the nasal cavity, hypopharynx, Waldeyer's ring, larynx and oral cavity (14-16). The involvement of extra-UADT sites is relatively rare in ENKTCL. Previous studies reported that UADT-ENKTCL and extra-UADT-ENKTCL have different clinical features and prognoses (17-19). The present study aimed therefore to investigate and analyze the characteristics and survival outcomes of patients from the United States (US) with stage IE and IIE primary UADT-ENKTCL of the nasal cavity by using the Surveillance, Epidemiology, and End Results (SEER) program database. In addition, by combining multiple independent factors, including age, stage, radiation and primary site, a nomogram based on patients overall survival (OS) was developed. This nomogram may be used to predict the OS and prognosis of patients with ENKTCL.

\section{Materials and methods}

Data source. Data were obtained from the SEER database (www. seer.cancer.gov), which includes 18 registries and comprises data from $\sim 28 \%$ of the US population. The White, Black, Hispanic, American Indian and Alaskan, Asian and Hawaiian/Pacific Islander populations represented $25,26,38,44$ and $50 \%$ of the total population, respectively, in the 18 registries (20-22).

Cases based on the third edition of the International Classification of Disease for Oncology (ICD-O-3) were selected (8). In this study, patients with ENKTCL were identified 
Identified patients with NK/T cell lymphoma diagnosed between

2000 and 2013 in SEER 18 registries

[ICD-O-3(histology) $=9719](n=739)$

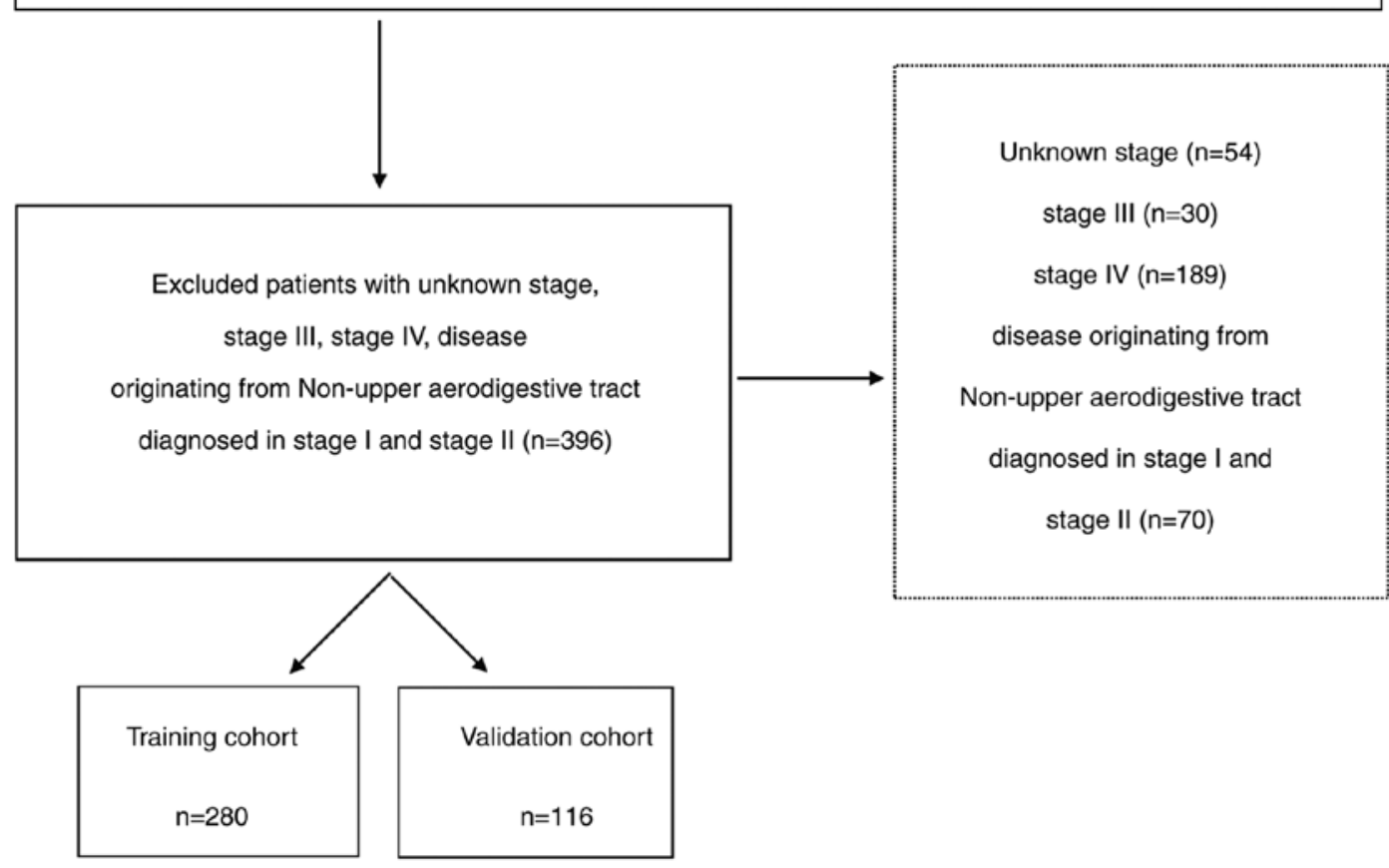

Figure 1. Flow diagram describing the evaluation and selection of patients with extranodal natural killer/T-cell lymphoma. ICD-O-3, International Classification of Disease for Oncology; NK/T, natural killer/T cell; SEER, Surveillance, Epidemiology, and End Results.

using the ICD-O-3 code for histology (9719, ENKTCL). In particular, patients with stage IE and IIE UADT-ENKTCL were selected; however, patients with unknown or higher stage UADT-ENKTCL and with stage I and II non-UADT-ENKTCL were excluded (Fig. 1). A total of 396 patients were eventually enrolled in the present study and were divided into training $(n=280)$ and validation $(n=116)$ cohorts.

Statistical analysis. Data were collected from the SEER database using the SEER stat 8.3.5 software (https://seer.cancer. gov/data/). Statistical analyses were performed using the statistical software packages SPSS 21.0 (IBM Corp.) and R-project version 3.5.1 (http://www.r-project.org/) for Windows. OS curves were analyzed using the Kaplan-Meier method and the differences between groups were compared using the log-rank test. Univariate and multivariate analyses and calculation of hazard ratio (HR) were performed using the Cox regression model. A nomogram based on multivariate analysis by the rms package (https://cran.r-project.org/web/packages/rms/index. html) in Rand Harrell's C statistic was built and calibration curves were used to estimate the accuracy of the prediction model $(23,24)$. $\mathrm{P}<0.05$ was considered to indicate a statistically significant difference.

\section{Results}

Patient characteristics. A total of 396 patients with UADT-ENKTCL identified in the SEER database were included in the present study. In the entire study cohort, median follow-up time was $\sim 18$ months (range, $0-152$ months). Median age at diagnosis was $\sim 52$ years (range, $8-93$ years). There were 178 deaths among the 396 patients at 2-140 months, accounting for $44.9 \%$ of the cohort. The clinical characteristics of patients in the training and validation cohorts are listed in Table I.

Univariate and multivariate analyses of $O S$ in the training cohort. In the training cohort, the variables in univariate Cox regression analysis were included as follows: Sex, ethnicity, stage, primary site, radiation therapy, surgery and age. Among these variables, stage, primary site, radiation therapy and age were significantly correlated with OS $(\mathrm{P}<0.05$; Table II). The survival curves are presented in Fig. 2. Due to the limited availability of chemotherapy data, this treatment variable was not included in the analysis. In the multivariate analyses, factors with $\mathrm{P}<0.1$, including age, stage, primary site, radiation therapy and stage primary site, which is defined as the interaction of two variables, were included for the Cox regression analysis. The results demonstrated that age, stage, primary site and radiation therapy were independently associated with unfavorable OS (Table II).

Nomogram development and validation. A nomogram was established based on the results of multivariate analyses. Age, stage, primary site and radiation therapy were included in the nomogram. A weighted total score was calculated for each factor and was then used to calculate and estimate the 3-year OS and the probability for 5-year OS (Fig. 3). Harrell's $\mathrm{C}$ statistic of the nomogram was calculated to be 0.717 in the training cohort and 0.737 in the validation cohort, which indicated that that the discriminatory capacity of the nomogram 
Table I. Clinical characteristics of patients with extranodal natural killer/T-cell lymphoma in the training and validation cohorts.

\begin{tabular}{|c|c|c|c|c|}
\hline Variable & Training cohort, $\mathrm{n}(\%)$ & Validation cohort, $\mathrm{n}(\%)$ & Total, $\mathrm{n}$ & P-value \\
\hline \multicolumn{5}{|l|}{ Age, years } \\
\hline$\leq 45$ & $110(39.3)$ & $42(36.2)$ & 152 & \multirow[t]{3}{*}{0.751} \\
\hline$>45$ and $\leq 65$ & $107(38.2)$ & $49(42.2)$ & 156 & \\
\hline$>65$ & $63(22.5)$ & $25(21.6)$ & 88 & \\
\hline \multicolumn{5}{|l|}{ Sex } \\
\hline Male & $182(65)$ & $81(69.8)$ & 257 & \multirow[t]{2}{*}{0.903} \\
\hline Female & $98(35)$ & $35(30.2)$ & 139 & \\
\hline \multicolumn{5}{|l|}{ Ethnicity } \\
\hline White & $199(72.1)$ & $88(75.9)$ & 287 & \multirow[t]{2}{*}{0.367} \\
\hline Other & 77 (27.9) & $27(24.1)$ & 104 & \\
\hline \multicolumn{5}{|l|}{ Stage } \\
\hline IE & $190(67.9)$ & $77(66.4)$ & 267 & \multirow[t]{2}{*}{0.775} \\
\hline IIE & $90(32.1)$ & $39(33.6)$ & 129 & \\
\hline \multicolumn{5}{|l|}{ B symptoms } \\
\hline Yes & $62(30)$ & $23(27.6)$ & 85 & \multirow[t]{2}{*}{0.939} \\
\hline No & $145(70)$ & $55(72.4)$ & 200 & \\
\hline \multicolumn{5}{|l|}{ Primary site } \\
\hline Nasal cavity and sinus & $216(77.1)$ & $93(80.2)$ & 309 & \multirow[t]{2}{*}{0.520} \\
\hline Other & $64(22.9)$ & $23(19.8)$ & 87 & \\
\hline \multicolumn{5}{|l|}{ Radiation } \\
\hline Yes & $183(66.3)$ & $83(71.6)$ & 266 & \multirow[t]{2}{*}{0.508} \\
\hline No & $93(33.7)$ & $33(28.4)$ & 126 & \\
\hline \multicolumn{5}{|l|}{ Surgery } \\
\hline Yes & $201(71.8)$ & $87(75)$ & 288 & \multirow[t]{2}{*}{0.513} \\
\hline No & 79 (28.2) & $29(25)$ & 108 & \\
\hline \multicolumn{5}{|l|}{ Chemotherapy } \\
\hline Yes & & & 264 & \\
\hline No/unknown & & & 132 & \\
\hline
\end{tabular}

was relatively clear and accurate. In addition, the calibration curves revealed excellent consistency between predicted OS and actual OS (Fig. 4).

Further analysis of patients' outcomes associated with treatment methods. A subgroup analysis was performed involving 264 patients receiving chemotherapy. The subgroup analysis results are presented in Table III. Univariate analysis demonstrated that stage, primary site and radiation therapy were significant factors in the chemotherapy group. Variables with $\mathrm{P}<0.1$ on univariate analysis were included in multivariate analysis. Age, which is generally considered as a clinically important variable, was included in the Cox regression analysis. Stage and radiation therapy remained independent prognostic indicators. This result indicated that, based on chemotherapy, radiation therapy was beneficial for increasing OS.

\section{Discussion}

Stage IE and IIE UADT-ENKTCL account for the largest proportion of ENKTCL cases and have unique clinical features, such as tumors usually infiltrating the nasopharynx or surrounding areas (15). Compared with other ENKTCL cases, stage IE and IIE UADT-ENKTCL cases usually exhibit lower lactate dehydrogenase levels and better performance status (25). In recent years, radiotherapy has been considered to be the most effective treatment (25). In the present study, a novel nomogram was built for this particular patient group based on the characteristics of the US population. This nomogram was validated in a validation cohort.

A nomogram is a simple and intuitive statistical tool used to calculate survival probability by incorporating relevant determinants of a disease. It may therefore be a useful tool for clinicians to make clinical decisions $(26,27)$. In particular, in the field of oncology, nomograms can serve in designing various prediction models for survival, recurrence and metastasis (28-32).

The present study demonstrated that age, primary site, radiation therapy and stage were independent prognostic factors for OS. Previous studies reported that age is an important prognostic factor for OS $(33,34)$. In order to further stratify the nomogram, two cut-off points for age (45 and 
A

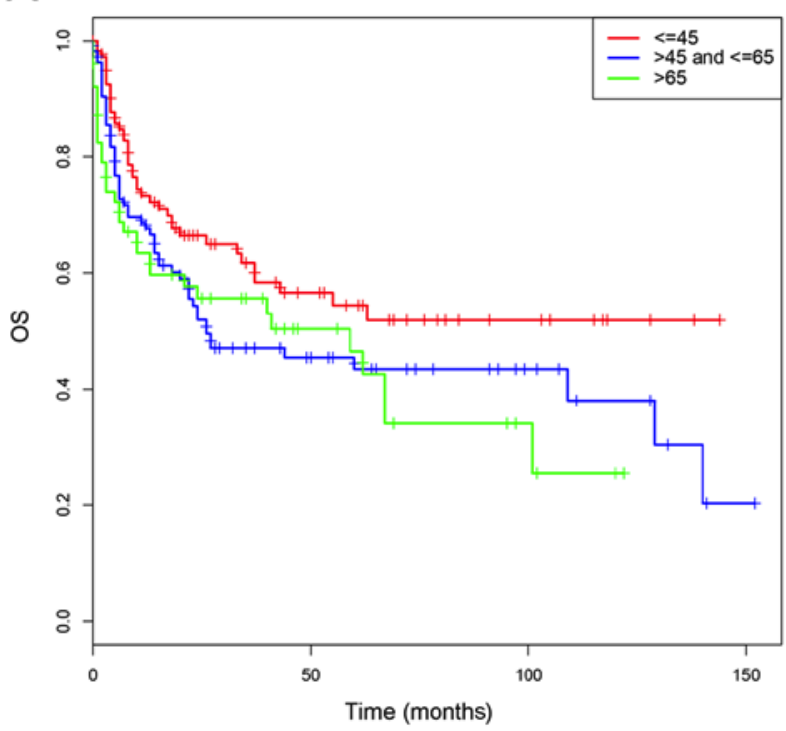

C

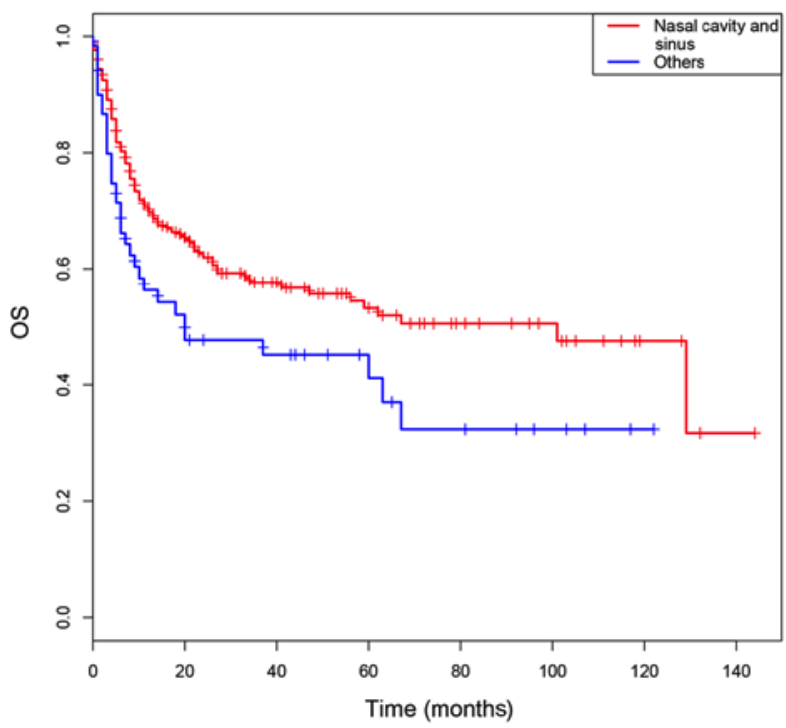

B

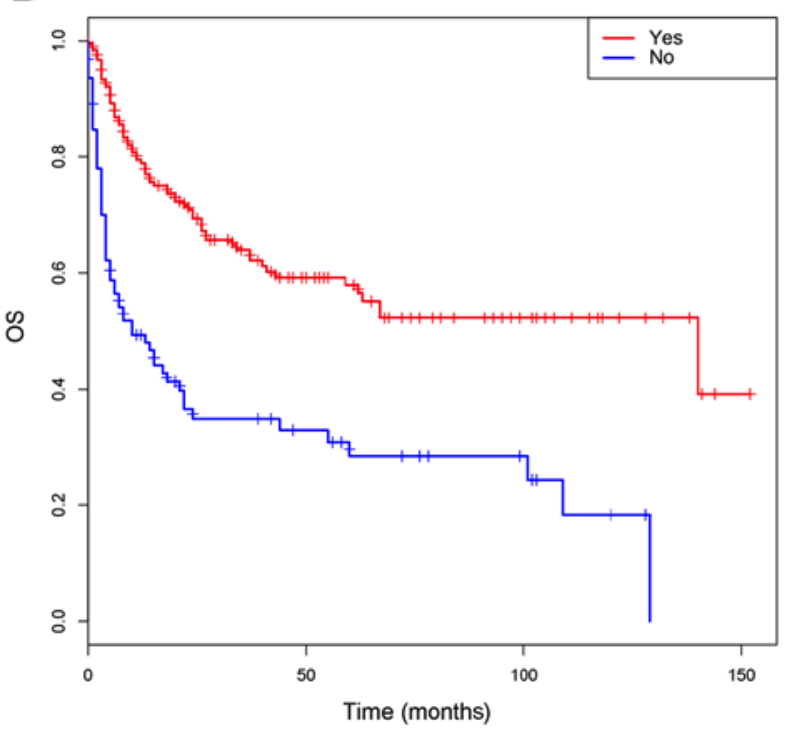

D

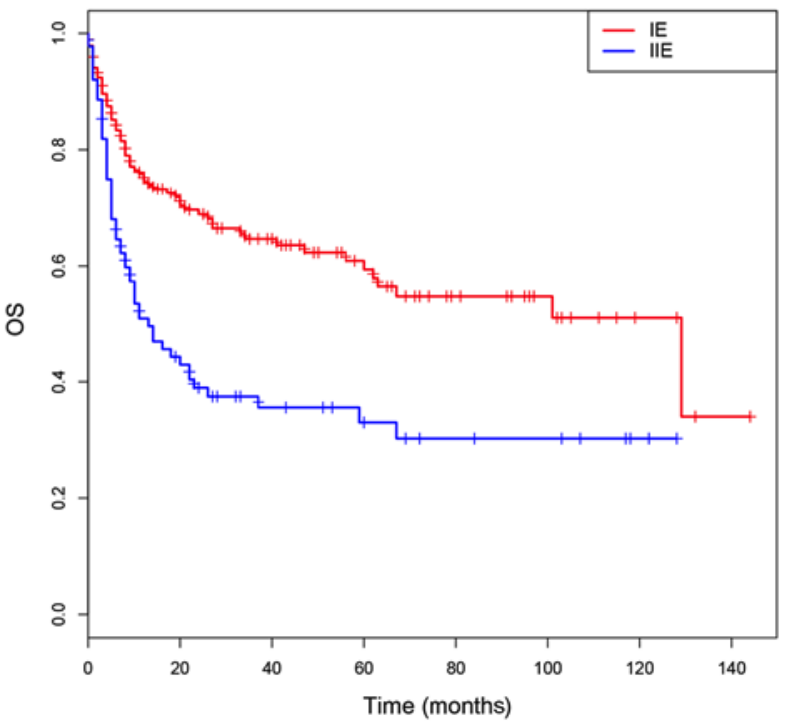

Figure 2. Kaplan-Meier curves of OS by (A) age, (B) radiation, (C) primary site and (D) stage. OS, overall survival.

65 years) were determined. The results demonstrated that $\mathrm{HR}$ of OS increased with age; however, older patients had worsen survival, notably patients $>65$ year old. The primary site was also an important prognostic variable for ENKTCL. It has been demonstrated that patients with extra-nasal UADT-ENKTCL are more likely to have worsen OS compared with those with ENKTCL $(25,35,36)$. Data about chemotherapy treatment were divided into 'receiving chemotherapy' and 'No/Unknown' groups; however, due to the uncertainty of certain data, this information was unusable for univariate or multivariate analysis. Subsequently, the analysis focused on the efficacy of additional radiotherapy in patients who were receiving chemotherapy. Previous studies reported that initial treatment with radiation therapy and subsequent chemotherapy is superior to chemotherapy alone, and to chemotherapy followed by radiation $(4,37)$. The present study also confirmed that radiation therapy was still an independent prognostic factor in the chemotherapy subgroup, which was consistent with the results of previous studies $(38,39)$. Avilés et al (38) and You et al (39) reported that radiation therapy, as complementary treatment for chemotherapy or as palliative treatment following chemotherapy, is superior to chemotherapy alone. With regards to the stage, numerous studies have compared the prognoses of stage IE and IIE ENKTCL with that of stage IIIE and IVE ENKTCL $(35,40,41)$, and these studies reported that stage IIIE and IVE ENKTCL have worse prognostic results. However, only a few studies compared the prognoses of stage IE ENKTCL with that of stage IIE ENKTCL, including the studies by Wang et al (42) and Dai et al (43), which revealed that patients with stage IE ENKTCL have a longer OS, which was consistent with the results of the present study. In addition, the analysis of the subgroup of the chemotherapy group revealed that stage remained an important prognostic variable. Notably, studies from Wang et al (42) and Dai et al (43) reported that 
Table II. Univariate and multivariate analysis for overall survival of patients with extranodal natural killer/T-cell lymphoma.

\begin{tabular}{|c|c|c|c|c|c|}
\hline \multirow[b]{2}{*}{ Variable } & \multirow[b]{2}{*}{ 5-year OS (\%) } & \multicolumn{2}{|c|}{ Univariate analysis } & \multicolumn{2}{|c|}{ Multivariate analysis } \\
\hline & & Hazard ratio $(95 \% \mathrm{CI})$ & P-value & Hazard ratio $(95 \% \mathrm{CI})$ & P-value \\
\hline \multicolumn{6}{|l|}{ Age, years } \\
\hline$\leq 45$ & 21.8 & & & & \\
\hline$>45$ and $\leq 65$ & 19.6 & $1.433(0.957-2.146)$ & & $1.253(0.832-1.889)$ & \\
\hline$>65$ & 19.0 & $1.609(1.017-2.547)$ & 0.025 & $1.823(1.147-2.896)$ & 0.044 \\
\hline \multicolumn{6}{|l|}{ Sex } \\
\hline Male & 17.0 & & & & \\
\hline Female & 26.5 & $0.701(0.483-1.018)$ & 0.062 & & \\
\hline \multicolumn{6}{|l|}{ Ethnicity } \\
\hline White & 19.1 & & & & \\
\hline Other & 22.1 & $0.923(0.628-1.356)$ & 0.682 & & \\
\hline \multicolumn{6}{|l|}{ Stage } \\
\hline $\mathrm{IE}$ & 23.2 & & & & \\
\hline IIE & 14.4 & $2.065(1.458-2.923)$ & $<0.001$ & $2.143(1.498-3.066)$ & $<0.001$ \\
\hline \multicolumn{6}{|l|}{ B symptoms } \\
\hline No & 19.3 & & & & \\
\hline Yes & 17.7 & $1.251(0.797-1.962)$ & 0.330 & & \\
\hline \multicolumn{6}{|l|}{ Primary site } \\
\hline Nasal cavity and sinus & 22.7 & & & & \\
\hline Other & 12.5 & $2.030(1.395-2.955)$ & 0.029 & $1.686(1.149-2.473)$ & 0.008 \\
\hline \multicolumn{6}{|l|}{ Radiation } \\
\hline Yes & 24.6 & & & & \\
\hline No & 11.8 & $2.677(1.888-3.795)$ & $<0.001$ & $2.752(1.927-3.932)$ & $<0.001$ \\
\hline \multicolumn{6}{|l|}{ Surgery } \\
\hline Yes & 21.4 & & & & \\
\hline No & 17.7 & $0.730(0.487-1.094)$ & 0.127 & & \\
\hline
\end{tabular}

OS, overall survival; CI, confidence interval.

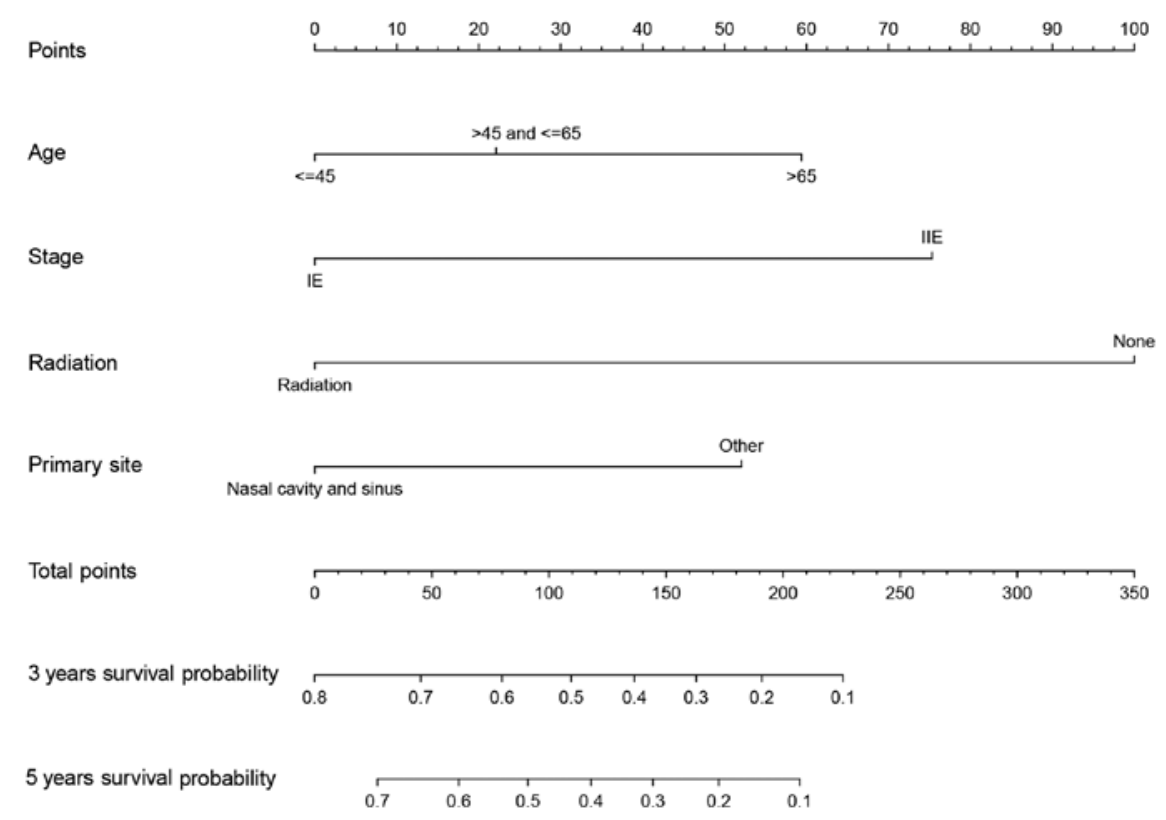

Figure 3. Nomograms for prediction of the 3-year and 5-year overall survival of patients with stages IE and IIE extranodal natural killer/T-cell lymphoma of the nasal cavity. OS, overall survival 
Table III. Univariate and multivariate subgroup analysis for overall survival of patients with extranodal natural killer/T-cell lymphoma that received chemotherapy.

\begin{tabular}{|c|c|c|c|c|c|}
\hline \multirow[b]{2}{*}{ Variable } & \multirow[b]{2}{*}{ 5-year OS (\%) } & \multicolumn{2}{|c|}{ Univariate analysis } & \multicolumn{2}{|c|}{ Multivariate analysis } \\
\hline & & Hazard ratio $(95 \% \mathrm{CI})$ & P-value & Hazard ratio $(95 \% \mathrm{CI})$ & P-value \\
\hline \multicolumn{6}{|l|}{ Age, years } \\
\hline$\leq 45$ & 62.7 & & & & \\
\hline$>45$ and $\leq 65$ & 56.4 & $1.156(0.776-1.722)$ & & & \\
\hline$>65$ & 576.1 & $1.111(0.599-2.061)$ & 0.772 & & \\
\hline \multicolumn{6}{|l|}{ Sex } \\
\hline Male & 57.9 & & & & \\
\hline Female & 62.4 & $0.785(0.528-1.168)$ & 0.232 & & \\
\hline \multicolumn{6}{|l|}{ Race } \\
\hline White & 58 & & & & \\
\hline Other & 53.8 & $1.073(0.709-1.622)$ & 0.74 & & \\
\hline \multicolumn{6}{|l|}{ Stage } \\
\hline IE & 69 & & & & \\
\hline IIE & 41.9 & $2.250(1.548-3.270)$ & $<0.001$ & $2.316(1.590-3.374)$ & $<0.001$ \\
\hline \multicolumn{6}{|l|}{ B symptoms } \\
\hline No & 63.8 & & & & \\
\hline Yes & 70.6 & $0.910(0.529-1.568)$ & 0.735 & & \\
\hline \multicolumn{6}{|l|}{ Primary site } \\
\hline Nasal cavity and sinus & 62.1 & & & & \\
\hline Other & 48 & $1.840(1.19-2.845)$ & 0.006 & & \\
\hline \multicolumn{6}{|l|}{ Radiation } \\
\hline Yes & 67.5 & & & & \\
\hline No & 37.1 & $2.621(1.787-3.842)$ & $<0.001$ & $2.700(1.841-3.962)$ & $<0.001$ \\
\hline \multicolumn{6}{|l|}{ Surgery } \\
\hline Yes & 58.5 & & & & \\
\hline No & 61.7 & $0.934(0.621-1.404)$ & 0.741 & & \\
\hline
\end{tabular}

OS, overall survival; CI, confidence interval.
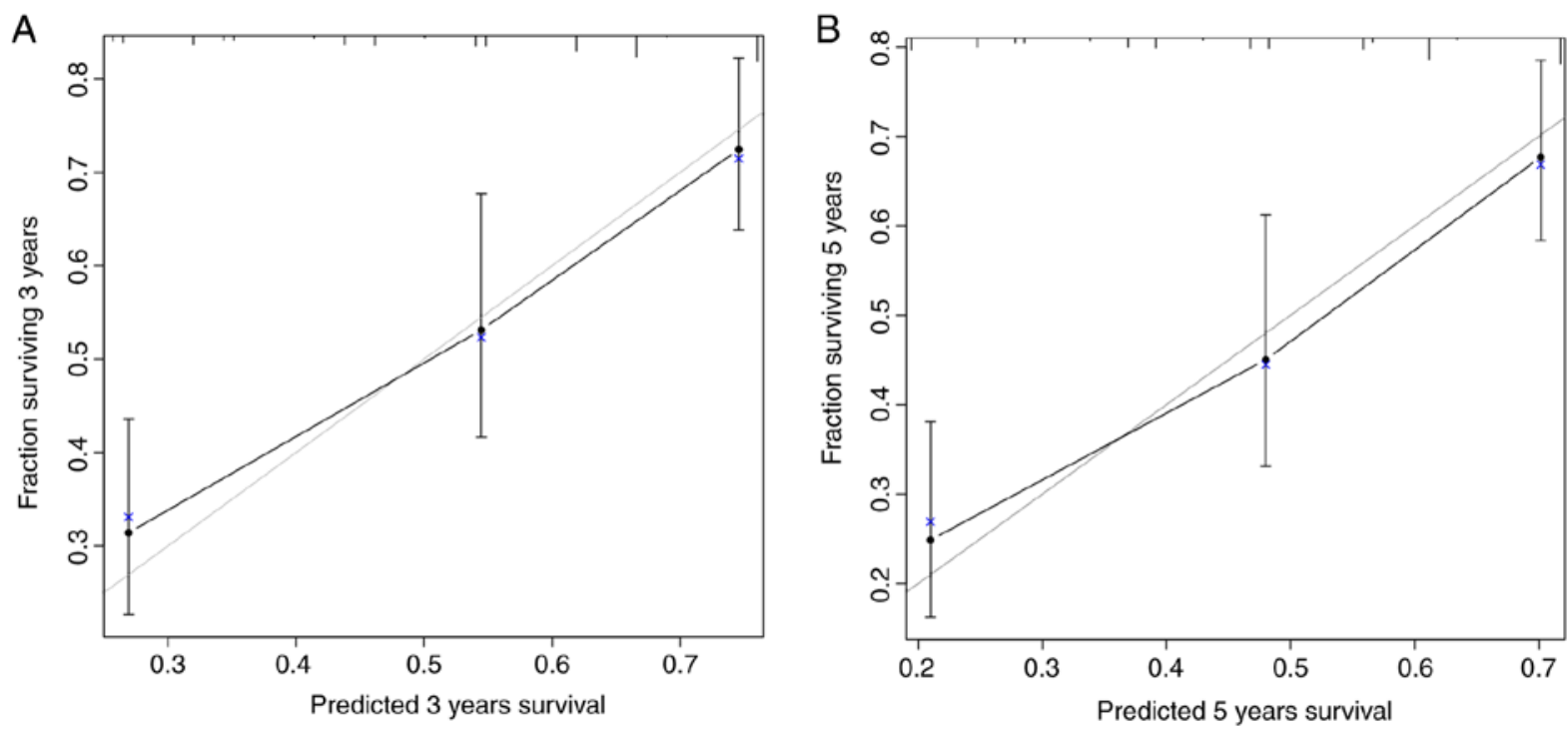

Figure 4. (A) Calibration curve of the nomogram for predicting 3-year OS of patients with stages IE and IIE extranodal natural killer/T-cell lymphoma of the nasal cavity. (B) Calibration curve of the nomogram for predicting 5-year OS of patients with stages IE and IIE extranodal natural killer/T-cell lymphoma of the nasal cavity. OS, overall survival. 
in early-stage ENKTCL, B symptoms, including fever, weight loss and night sweats, are not associated with prognosis. The results from the present study were consistent with those from these previous studies $(41,42)$, and were also similar to those from studies on some early-stage lymphomas $(44,45)$.

The present study presented certain limitations. Firstly, data selection from the SEER database may potentially cause selection bias, since this is prevalent in all non-prospective, nonrandomized studies. Secondly, SEER database does not include clinically meaningful variables, including the expression levels of Ki-67, lactate dehydrogenase, $\beta 2$-microglobulin and local tumor invasiveness. Although the sample size was large, the present study is a retrospective study and needs to be validated in a cohort study. Thirdly, since information about patient treatment in the SEER database was incomplete, the present study did not include information on specific modalities and doses of radiotherapy and chemotherapy.

In conclusion, the present study analyzed prognostic data of stage IE and IIE UADT-ENKTCL from the SEER database and developed a prognostic nomogram. This nomogram may predict the OS of patients with ENKTCL by using some clinically common variables. This nomogram may guide clinicians in better decision-making and have crucial clinical applications.

\section{Acknowledgements}

Not applicable.

\section{Funding}

The present study was supported by the National Natural Science Foundation of China (grant no. 81570203).

\section{Availability of data and materials}

The datasets generated and/or analyzed during the present study are available in SEER stat 8.3.5 software (https://seer. cancer.gov/data/).

\section{Authors' contributions}

MZ and GW designed the study, wrote the original draft and revised the manuscript. YC, XW, XL and LL contributed to the collection and analysis of the data and the preparation of figures and tables.All authors read and approved the final manuscript

\section{Ethical approval and consent to participate}

Not applicable.

\section{Patient consent for publication}

Not applicable.

\section{Competing interests}

The authors declare that they have no competing interests.

\section{References}

1. Li X, Cui Y, Sun Z, Zhang L, Li L, Wang X, Wu J, Fu X, Ma W, Zhang $\mathrm{X}$, et al: DDGP versus SMILE in newly diagnosed advanced natural killer/T-Cell lymphoma: A randomized controlled, multicenter, open-label study in China. Clin Cancer Res 22: 5223-5228, 2016.

2. Aozasa K and Zaki MA: Epidemiology and pathogenesis of nasal NK/T-cell lymphoma: A mini-review. ScientificWorldJournal 11: 422-428, 2011.

3. Ai WZ, Chang ET, Fish K, Fu K, Weisenburger DD and Keegan TH: Racial patterns of extranodal natural killer/T-cell lymphoma, nasal type, in California: A population-based study. Br J Haematol 156: 626-632, 2012.

4. $\mathrm{Au}$ WY, Weisenburger DD, Intragumtornchai T, Nakamura S, Kim WS, Sng I, Vose J, Armitage JO and Liang R; International Peripheral T-Cell Lymphoma Project: Clinical differences between nasal and extranasal natural killer/T-cell lymphoma: A study of 136 cases from the International Peripheral T-Cell Lymphoma Project. Blood 113: 3931-3937, 2009.

5. Suzuki R, Suzumiya J, Yamaguchi M, Nakamura S, Kameoka J, Kojima H, Abe M, Kinoshita T, Yoshino T, Iwatsuki K, et al: Prognostic factors for mature natural killer (NK) cell neoplasms: Aggressive NK cell leukemia and extranodal NK cell lymphoma, nasal type. Ann Oncol 21: 1032-1040, 2010.

6. Kim TM, Lee SY, Jeon YK, Ryoo BY, Cho GJ, Hong YS, Kim HJ, Kim SY, Kim CS, Kim S, et al: Clinical heterogeneity of extranodal NK/T-cell lymphoma, nasal type: A national survey of the Korean Cancer Study Group. Ann Oncol 19: 1477-1484, 2008.

7. Vazquez A, Khan MN, Blake DM, Sanghvi S, Baredes S and Eloy JA: Extranodal natural killer/T-Cell lymphoma: A population-based comparison of sinonasal and extranasal disease. Laryngoscope 124: 888-895, 2014.

8. Fritz A: ICD-O-3 terminology approved for use with cases diagnosed January 1, 2014 and after.J Registry Manag 40: 140-143, 2013.

9. Liu X, Huang E, Wang Y, He Y, Luo H, Zhong M, Qiu D, Li C, Yang H, He G, et al: Dosimetric comparison of helical tomotherapy, VMAT, fixed-field IMRT and 3D-conformal radiotherapy for stage I-II nasal natural killer T-cell lymphoma. Radiat Oncol 12: 76, 2017.

10. Ma X, Guo Y, Pang Z, Wang B, Lu H, Gu YJ and Guo X: A randomized phase II study of CEOP with or without semustine as induction chemotherapy in patients with stage IE/IIE extranodal NK/T-cell lymphoma, nasal type in the upper aerodigestive tract. Radiother Oncol 93: 492-497, 2009.

11. Kim SJ, Yang DH, Kim JS, Kwak JY, Eom HS, Hong DS, Won JH, Lee JH, Yoon DH, Cho J, et al: Concurrent chemoradiotherapy followed by L-asparaginase-containing chemotherapy, VIDL, for localized nasal extranodal NK/T cell lymphoma: CISL08-01 phase II study. Ann Hematol 93: 1895-1901, 2014.

12. Kim WS, Song SY, Ahn YC, Ko YH, Baek CH, Kim DY, Yoon SS, Lee HG, Kang WK, Lee HJ, et al: CHOP followed by involved field radiation: Is it optimal for localized nasal natural killer/T-cell lymphoma? Ann Oncol 12: 349-352, 2001.

13. Kim SJ, Kim K, Kim BS, Kim CY, Suh C, Huh J, Lee SW, Kim JS, Cho J, Lee GW, et al: Phase II trial of concurrent radiation and weekly cisplatin followed by VIPD chemotherapy in newly diagnosed, stage IE to IIE, nasal, extranodal NK/T-Cell Lymphoma: Consortium for Improving Survival of Lymphoma study. J Clin Oncol 27: 6027-6032, 2009.

14. Song MK, Chung JS, Yhim HY, Lim SN, Kim SJ, Han YH, Shim HK, Jung SH, Lee JJ and Yang DH: Tumor necrosis and complete resection has significant impacts on survival in patients with limited-stage upper aerodigestive tract NK/T cell lymphoma. Oncotarget 8: 79337-79346, 2017.

15. Li YX, Fang H, Liu QF, Lu J, Qi SN, Wang H, Jin J, Wang WH, Liu YP, Song YW, et al: Clinical features and treatment outcome of nasal-type NK/T-cell lymphoma of Waldeyer ring. Blood 112: 3057-3064, 2008.

16. Gao DL, Fu QQ, Zhang TT, Li SL, Pan Y and Zhai QL: Analysis of clinicopathological characteristics and prognosis of 112 patients with primary Waldeyer's ring lymphoma. Zhongguo Shi Yan Xue Ye Xue Za Zhi 23: 1301-1308, 2015 (In Chinese).

17. Huang JJ, Zhu YJ, Xia Y, Zhao W, Lin TY, Jiang WQ, Huang HQ and Li ZM: A novel prognostic model for extranodal natural killer/T-cell lymphoma. Med Oncol 29: 2183-2190, 2012.

18. Jo JC, Yoon DH, Kim S, Lee BJ, Jang YJ, Park CS, Huh J, Lee SW, Ryu JS and Suh C: Clinical features and prognostic model for extranasal NK/T-cell lymphoma. Eur J Haematol 89: 103-110, 2012. 
19. Pong pruttipan T, Sukpanichnant $S$, Assanasen T, Wannakrairot $P$, Boonsakan P, Kanoksil W, Kayasut K, Mitarnun W, Khuhapinant A, Bunworasate U, et al: Extranodal NK/T-cell lymphoma, nasal type, includes cases of natural killer cell and $\alpha \beta, \gamma \delta$, and $\alpha \beta / \gamma \delta$ T-cell origin: A comprehensive clinicopathologic and phenotypic study. Am J Surg Pathol 36: 481-499, 2012.

20. Ebied A, Thanh Huan V, Makram OM, Sang TK, Ghorab M, Ngo HT, Iraqi A, Kamel MG, Dang TN, Vuong NL, et al: The role of primary lymph node sites in survival and mortality prediction in Hodgkin lymphoma: A SEER population-based retrospective study. Cancer Med 7: 953-965, 2018.

21. Liu PP, Wang KF, Jin JT, Bi XW, Sun P, Wang Y, Yang H, Li ZM, Jiang WQ and Xia Y: Role of radiation therapy in primary breast diffuse large B-cell lymphoma in the Rituximab era: A SEER database analysis. Cancer Med 7: 1845-1851, 2018.

22. Adams SV, Newcomb PA and Shustov AR: Racial patterns of peripheral T-Cell lymphoma incidence and survival in the United States. J Clin Oncol 34: 963-971, 2016.

23. Pencina MJ and D'Agostino RB: Overall $\mathrm{C}$ as a measure of discrimination in survival analysis: Model specific population value and confidence interval estimation. Stat Med 23: 2109-2123, 2004.

24. Harrell FE Jr, Lee KL and Mark DB: Multivariable prognostic models: Issues in developing models, evaluating assumptions and adequacy, and measuring and reducing errors. Stat Med 15 361-387, 1996

25. Niu SQ, Yang Y, Li YY, Wen G, Wang L, Li ZM, Wang HY, Zhang LL, Xia YF and Zhang YJ: Primary site and regional lymph node involvement are independent prognostic factors for early-stage extranodal nasal-type natural killer/T cell lymphoma. Chin J Cancer 35: 34, 2016.

26. Balachandran VP, Gonen M, Smith JJ and DeMatteo RP: Nomograms in oncology: More than meets the eye. Lancet Oncol 16: e173-e180, 2015.

27. Miao DL, Song W, Qian J, Zhu ZG, Wu Q, Lv CG and Chen L: Development and validation of a nomogram for predicting overall survival in pancreatic neuroendocrinetumors. Transl Oncol 11: 1097-1103, 2018.

28. Hayashi Y, Xiao L, Suzuki A, Blum MA, Sabloff B, Taketa T, Maru DM, Welsh J, Lin SH, Weston B, et al: A nomogram associated with high probability of malignant nodes in the surgical specimen after trimodality therapy of patients with oesophageal cancer. Eur J Cancer 48: 3396-3404, 2012.

29. Gold JS, Gönen M, Gutiérrez A, Broto JM, García-del-Muro X, Smyrk TC, Maki RG, Singer S, Brennan MF, Antonescu CR, et al: Development and validation of a prognostic nomogram for recurrence-free survival after complete surgical resection of localised primary gastrointestinal stromal tumour: A retrospective analysis. Lancet Oncol 10: 1045-1052, 2009

30. Zhang JX, Song W, Chen ZH, Wei JH, Liao YJ, Lei J, Hu M, Chen GZ, Liao B, Lu J, et al: Prognostic and predictive value of a microRNA signature in stage II colon cancer: A microRNA expression analysis. Lancet Oncol 14: 1295-1306, 2013.

31. Kattan MW, Karpeh MS, Mazumdar M and Brennan MF: Postoperative nomogram for disease-specific survival after an R0 resection for gastric carcinoma. J Clin Oncol 21: 3647-3650, 2003.

32. Zivanovic O, Jacks LM, Iasonos A, Leitao MM Jr, Soslow RA, Veras E, Chi DS, Abu-Rustum NR, Barakat RR, Brennan MF and Hensley ML: A nomogram to predict postresection 5-year overall survival for patients with uterine leiomyosarcoma. Cancer 118: 660-669, 2012.

33. Yang Y, Zhang YJ, Zhu Y, Cao JZ, Yuan ZY, Xu LM, Wu JX, Wang $\mathrm{W}, \mathrm{Wu} \mathrm{T}, \mathrm{Lu} \mathrm{B}$, et al: Prognostic nomogram for overall survival in previously untreated patients with extranodal NK/T-cell lymphoma, nasal-type: A multicenter study. Leukemia 29: 1571-1577, 2015.
34. Cao J, Lan S, Shen L, Si H, Xiao H, Yuan Q, Li X, Li H and Guo R: Hemoglobin level, a prognostic factor for nasal extranodal natural killer/T-cell lymphoma patients from stage I to IV: A validated prognostic nomogram. Sci Rep 7: 10982, 2017.

35. Liu QF, Wang WH, Wang SL, Liu YP, Huang WT, Lu N, Zhou LQ, Ouyang H, Jin J and Li YX: Immunophenotypic and clinical differences between the nasal and extranasal subtypes of upper aerodigestive tract natural killer/T-cell lymphoma. Int J Radiat Oncol Biol Phys 88: 806-813, 2014.

36. Fang H, Jin J, Wang WH, Wang SL, Zhou LQ and Li YX: Prognostic factors and treatment outcomes for patients with stage II extranodal nasal-type natural killer/T-cell lymphoma of the upper aerodigestive tract. Leuk Lymphoma 55: 1832-1837, 2014.

37. Huang MJ, Jiang Y, Liu WP, Li ZP, Li M, Zhou L, Xu Y, Yu CH, Li Q, Peng F, et al: Early or up-front radiotherapy improved survival of localized extranodal NK/T-cell lymphoma, nasal-type in the upper aerodigestive tract. Int J Radiat Oncol Biol Phys 70: 166-174, 2008.

38. Avilés A, Delgado S, Ruiz H, de la Torre A, Guzman R and Talavera A: Treatment of non-Hodgkin's lymphoma of Waldeyer's ring: Radiotherapy versus chemotherapy versus combined therapy. Eur J Cancer B Oral Oncol 32B: 19-23, 1996.

39. You JY, Chi KH, Yang MH, Chen CC, Ho CH, Chau WK, Hsu HC, Gau JP, Tzeng CH, Liu JH, et al: Radiation therapy versus chemotherapy as initial treatment for localized nasal natural killer (NK)/T-cell lymphoma: A single institute survey in Taiwan. Ann Oncol 15: 618-625, 2004.

40. Song G, Xiong GY, Fan Y, Huang C, Kang YM, Ji GJ, Chen JC, Xin ZC and Zhou LQ: The role of tumor size, ultrasonographic findings, and serum tumor markers in predicting the likelihood of malignant testicular histology. Asian J Androl 21: 196-200, 2019.

41. Yang QS, Zhao SH, Jiang Y, Jiang TY, Yuan SZ and Su H: Retrospective analysis of clinical features and prognosis of 84 patients with extranodal NK/T cell lymphoma in one center. Zhongguo Shi Yan Xue Ye Xue Za Zhi 25: 1390-1396, 2017 (In Chinese).

42. Wang KF, Chang BY, Chen XQ, Liu PP, Wuxiao ZJ, Wang ZH, Li S, Jiang WQ and Xia ZJ: A prognostic model based on pretreatment platelet lymphocyte ratio for stage IE/IIE upper aerodigestive tract extranodal NK/T cell lymphoma, nasal type. Med Oncol 31: 318, 2014.

43. Dai W, Jia B, Yang J, Zhou S, Liu P, He X, Qin Y, Gui L, Zhang C, Han X, et al: Development of new prognostic model based on pretreatment $\beta$ LRI and LLRI for stage IE/IIE upper aerodigestive tract ENKTL, nasal type. Oncotarget 8: 34787-34795, 2017.

44. Wang GB, Xu GL, Luo GY, Shan HB, Li Y, Gao XY, Li JJ and Zhang R: Primary intestinal non-Hodgkin's lymphoma: A clinicopathologic analysis of 81 patients. World J Gastroenterol 17: 4625-4631, 2011

45. Zhang S, Wang L, Yu D, Shen Y, Cheng S, Zhang L, Qian Y, Shen Z, Li Q and Zhao W: Localized primary gastrointestinal diffuse large B cell lymphoma received a surgical approach: An analysis of prognostic factors and comparison of staging systems in 101 patients from a single institution. World J Surg Oncol 13: 246, 2015.

This work is licensed under a Creative Commons Attribution-NonCommercial-NoDerivatives 4.0 International (CC BY-NC-ND 4.0) License. 